\title{
Chronological analysis of surgical and oncological outcomes after the treatment of perihilar cholangiocarcinoma
}

\author{
Sung Ho Lee, Gi Hong Choi, Dai Hoon Han, Kyung Sik Kim, Jin Sub Choi, and Seoung Yoon Rho \\ Division of Hepato-Biliary and Pancreatic Surgery, Department of Surgery, \\ Yonsei University College of Medicine, Seoul, Korea
}

\begin{abstract}
Backgrounds/Aims: Despite advances in surgical techniques and perioperative supportive care, radical resection of hilar cholangiocarcinoma is the only modality that can achieve long-term survival. We chronologically investigated surgical and oncological outcomes of hilar cholangiocarcinoma and analyzed the factors affecting overall survival. Methods: We retrospectively enrolled 165 patients with hilar cholangiocarcinoma who underwent liver resection with a curative intent. The patients were divided into groups based on the period when the surgery was performed: period I (2005-2011) and period II (2012-2018). The clinicopathological characteristics, perioperative outcomes, and survival outcomes were analyzed. Results: The patients' age, serum CA19-9 levels, and serum bilirubin levels at diagnosis were significantly higher in the period I group. There were no differences in pathological characteristics such as tumor stage, histopathologic status, and resection status. However, perioperative outcomes, such as estimated blood loss (1528.8 vs. $1034.1 \mathrm{~mL}, p=0.020)$ and postoperative severe complication rate $(51.3 \%$ vs. $26.4 \%, p=0.022)$, were significantly lower in the period II group. Regression analysis demonstrated that period I (hazard ratio $[\mathrm{HR}]=1.591 ; 95 \%$ confidence interval $[\mathrm{Cl}]=1.049-2.414$; $p=0.029$ ), preoperative serum bilirubin at diagnosis ( $\mathrm{HR}=1.585 ; 95 \% \mathrm{Cl}=1.058-2.374 ; p=0.026$ ), and tumor stage (III, IV) $(\mathrm{HR}=1.671 ; 95 \% \mathrm{Cl}: 1.133-2.464 ; p=0.010)$ were significantly associated with poor prognosis. The 5-year survival rate was better in the period II patients than in the period I patients $(35.1 \%$ vs. $21.0 \%, p=0.0071)$. Conclusions: The surgical and oncological outcomes were better in period II. Preoperative serum bilirubin and advanced tumor stage were associated with poor prognosis in patients with hilar cholangiocarcinoma. (Ann Hepatobiliary Pancreat Surg 2021;25:62-70)
\end{abstract}

Key Words: Hilar cholangiocarcinoma; Klatskin tumor; Chronological analysis; Surgical outcome; Oncological outcome; Survival

\section{INTRODUCTION}

Surgical resection is the only treatment modality that can achieve long-term survival outcomes after the treatment of hilar cholangiocarcinoma, a malignancy of the biliary epithelium of the hilum. ${ }^{1,2}$ Despite advances in surgical techniques and perioperative supportive care, the treatment of hilar cholangiocarcinoma remains challenging. Due to its infiltrative nature by longitudinal extension and its proximity to vital vascular structures, surgical resection of the tumor is limited and has unfavorable oncological outcomes. ${ }^{3,4}$ Extended major hepatectomy with concomitant vascular and biliary resection and reconstruction is associated with high perioperative morbidity and mortality rates, and, as such, the evolution of surgical treatment for hilar cholangiocarcinoma is ongoing.

To date, the actual 5-year survival rate for hilar cholangiocarcinoma is $14 \%-45 \%{ }^{5,6}$ In addition, the prognostic factors affecting long-term survival include lymph node metastasis, tumor resection margin status, and histological differentiation. ${ }^{7,8}$ Multicenter studies have reported that the broad spectrum of oncological outcomes originates from the variation in follow-up periods, inclusion of palliative resection, and numerous surgical approaches. Furthermore, there have been limited reports on the chronological analysis of hilar cholangiocarcinoma., 90

Therefore, in the current study, we aimed to chronologically investigate the surgical and oncological outcomes

Received: August 1, 2020; Revised: October 5, 2020; Accepted: October 5, 2020

Corresponding author: Seoung Yoon Rho

Division of Hepato-Biliary and Pancreatic Surgery, Department of Surgery, Yongin Severance Hospital, Yonsei University College of Medicine, 363 Dongbaekjukjeon-daero, Giheung-gu, Yongin 16995, Korea

Tel: +82-31-5189-8475, Fax: +82-031-5189-8568, E-mail: forsh7@yuhs.ac

Copyright (C) 2021 by The Korean Association of Hepato-Biliary-Pancreatic Surgery

This is an Open Access article distributed under the terms of the Creative Commons Attribution Non-Commercial License (http://creativecommons.org/ licenses/by-nc/4.0) which permits unrestricted non-commercial use, distribution, and reproduction in any medium, provided the original work is properly cited. Annals of Hepato-Biliary-Pancreatic Surgery - pISSN: 2508-5778 - elSSN: 2508-5859 
of hilar cholangiocarcinoma using a single-center cohort and analyzed the factors affecting overall survival (OS).

\section{MATERIALS AND METHODS}

\section{Patient population and classification of the chronological period}

We retrospectively reviewed the medical records of 165 patients who underwent surgical treatment with a curative intent for hilar cholangiocarcinoma from January 2005 to March 2018 at our hospital. The patients were divided into two groups according to the period when they underwent surgery: period I (2005-2011; $n=78)$ and period II (20122018; $n=87)$. The surgical treatment comprised liver resection, including more than three segments, with caudate lobectomy and Roux-en-Y hepaticojejunostomy. The types of surgery were right hemihepatectomy and extended right hemihepatectomy, left hemihepatectomy and extended left hemihepatectomy, and central bisectionectomy.

The need for informed consent was waived due to the retrospective nature of the study and because anonymous clinical data were used for the analyses. The study was approved by the institutional review board of the hospital (approval number: 4-2020-0676).

\section{Classification of hilar cholangiocarcinoma and perioperative management}

The type of hilar cholangiocarcinoma was classified according to the Bismuth-Corlette classification. ${ }^{11}$ The final pathology and stage were analyzed according to the American Joint Committee on Cancer, $8^{\text {th }}$ edition. R0 resection indicates a microscopically margin-negative resection, in which there was no gross or microscopic tumor remaining at the primary tumor bed as described in the final pathologic report. R1 resection indicates the removal of all macroscopic diseases, but with microscopic margins positive for tumors. Postoperative complications were classified according to the Clavien-Dindo classification. ${ }^{12}$ Postoperative liver failure was described in accordance with the classification criteria of the International Study Group of Liver Surgery. ${ }^{13}$

All patients underwent computed tomography (CT) and magnetic resonance imaging preoperatively. Portal vein embolization for remnant liver volume expansion was performed according to the remnant liver volume on CT scan- based liver volumetry before the planned surgery. The remnant liver volume was re-evaluated using CT scans obtained 2 weeks after porta vein embolization. If patients demonstrated severe obstructive jaundice with cholangitis, we considered preoperative biliary drainage, including percutaneous transhepatic biliary drainage, endoscopic retrograde biliary drainage, and endoscopic nasobiliary drainage, depending on the situation. The standard serum bilirubin level for performing radical resection is $3-4 \mathrm{mg} / \mathrm{dl}$ before surgery; however, this is based on the condition of the liver.

Surgical resection was performed by four surgeons in our institution. Major liver resections, including right hemihepatectomy, extended right hemihepatectomy, left hemihepatectomy, extended left hemihepatectomy, and central bisectionectomy, were performed using caudate lobectomy. For radical resection of the tumor, tumors that were visible by eye were removed, and examination of the proximal and distal margins was performed using frozen sections. For lymph node resection, the hepatic and duodenal ligament lymph nodes, including the right side of the celiac artery and the posterior pancreatic lymph nodes, were subjected to en bloc resection. The remaining lobe after resection was defined as the one with less bile duct invasion and no hepatic artery invasion and leaving the lobe through which healthy bile is drained. A total of 19 patients underwent a concomitant major vascular resection, including hepatic artery/portal vein resection and reconstruction.

Table 1. Comparison of the adjuvant chemotherapy regimens between the two groups (period I and period II)

\begin{tabular}{|c|c|c|c|}
\hline \multirow[t]{2}{*}{ Variables } & $\begin{array}{c}\text { Period I } \\
(2005-2011)\end{array}$ & $\begin{array}{c}\text { Period II } \\
(2012-2018)\end{array}$ & \multirow[t]{2}{*}{$p$-value } \\
\hline & $(\mathrm{n}=78)$ & $(\mathrm{n}=87)$ & \\
\hline \multicolumn{2}{|c|}{ Gemcitabine-based regimen } & & 0.871 \\
\hline No & $42(53.8 \%)$ & $49(56.3 \%)$ & \\
\hline Yes & $36(46.2 \%)$ & $38(43.7 \%)$ & \\
\hline \multicolumn{2}{|c|}{ Capecitabine-based regimen } & & 0.882 \\
\hline No & $74(94.9 \%)$ & $81(93.1 \%)$ & \\
\hline Yes & $4(5.1 \%)$ & $6(6.9 \%)$ & \\
\hline \multicolumn{2}{|c|}{ Fluorouracil-based regimen } & & 0.437 \\
\hline No & $53(67.9 \%)$ & $53(60.9 \%)$ & \\
\hline Yes & $25(32.1 \%)$ & $34(39.1 \%)$ & \\
\hline \multicolumn{2}{|c|}{ Cisplatin-based regimen } & & 0.480 \\
\hline No & $36(46.2 \%)$ & $46(52.9 \%)$ & \\
\hline Yes & $42(53.8 \%)$ & $41(47.1 \%)$ & \\
\hline
\end{tabular}


Postoperative management of the patients was generally performed in the general ward. Pain was managed using patient-controlled epidural analgesia, and enteral feeding was started on postoperative day 3-5. All patients underwent CT on postoperative day 5. After discharge, routine follow-up imaging was performed at an outpatient clinic and adjuvant therapy was considered depending on the final pathology report.

\section{Adjuvant treatment}

According to the final pathologic report, patients with $\mathrm{R} 1$ resection or higher or $\mathrm{T} 2$ grade or higher or those who

Table 2. Comparison of the clinical characteristics between the two groups (period I and period II)

\begin{tabular}{|c|c|c|c|}
\hline \multirow[t]{2}{*}{ Variables } & $\begin{array}{c}\text { Period I } \\
(2005-2011)\end{array}$ & $\begin{array}{c}\text { Period II } \\
(2012-2018)\end{array}$ & \multirow[t]{2}{*}{$p$-value } \\
\hline & $(\mathrm{n}=78)$ & $(\mathrm{n}=87)$ & \\
\hline Sex & & & 0.097 \\
\hline Male & $45(57.7 \%)$ & $62(71.3 \%)$ & \\
\hline Female & $33(42.3 \%)$ & $25(28.7 \%)$ & \\
\hline Age (years) & $62.2 \pm 10.0$ & $65.6 \pm 8.6$ & 0.021 \\
\hline Serum albumin $(g / d l)$ & $3.5 \pm 0.4$ & $3.4 \pm 0.5$ & 0.144 \\
\hline Serum bilirubin level at diagnosis $(\mathrm{mg} / \mathrm{dl})$ & $7.6 \pm 6.8$ & $5.0 \pm 5.6$ & 0.008 \\
\hline Serum bilirubin level 1 day before surgery $(\mathrm{mg} / \mathrm{dl})$ & $1.8 \pm 1.3$ & $1.6 \pm 1.2$ & 0.322 \\
\hline Serum AST (IU/L) & $44.8 \pm 28.2$ & $48.9 \pm 37.4$ & 0.426 \\
\hline Serum ALT (IU/L) & $51.1 \pm 67.4$ & $51.8 \pm 66.2$ & 0.946 \\
\hline Serum ALP(IU/L) & $250.4 \pm 226.4$ & $225.1 \pm 144.5$ & 0.402 \\
\hline Serum $\gamma \mathrm{GT}(\mathrm{IU} / \mathrm{L})$ & $401.4 \pm 491.1$ & $360.6 \pm 288.3$ & 0.576 \\
\hline CA 19-9 level at diagnosis $(\mathrm{U} / \mathrm{ml})$ & $1526.6 \pm 4076.9$ & $603.0 \pm 1807.6$ & 0.069 \\
\hline CA $19-91$ day before surgery $(\mathrm{U} / \mathrm{ml})$ & $1306.3 \pm 3856.3$ & $362.1 \pm 884.9$ & 0.039 \\
\hline Preoperative cholangitis & & & 0.636 \\
\hline No & $33(42.3 \%)$ & $36(41.4 \%)$ & \\
\hline Yes & $45(57.7 \%)$ & $51(58.6 \%)$ & \\
\hline Decompression method & & & 0.124 \\
\hline None & $15(19.2 \%)$ & $22(25.3 \%)$ & \\
\hline PTBD & $41(52.6 \%)$ & $30(34.5 \%)$ & \\
\hline ERCP (ERBD or ENBD) & $22(28.2 \%)$ & $35(40.2 \%)$ & \\
\hline Bismuth-Corlette classification & & & 0.239 \\
\hline I & $2(2.6 \%)$ & $4(4.6 \%)$ & \\
\hline II & $11(14.1 \%)$ & $7(8.0 \%)$ & \\
\hline IIIa & $29(37.2 \%)$ & $35(40.2 \%)$ & \\
\hline IIIb & $10(12.8 \%)$ & $20(23.0 \%)$ & \\
\hline IV & $26(33.3 \%)$ & $21(24.1 \%)$ & \\
\hline Preoperative portal vein embolization & & & 0.174 \\
\hline No & $62(79.5 \%)$ & $60(69.0 \%)$ & \\
\hline Yes & $16(20.5 \%)$ & $27(31.0 \%)$ & \\
\hline Neoadjuvant chemotherapy & & & 0.709 \\
\hline No & $73(93.6 \%)$ & $79(90.8 \%)$ & \\
\hline Yes & $5(6.4 \%)$ & $8(9.2 \%)$ & \\
\hline Adjuvant chemotherapy & & & 0.335 \\
\hline No & $26(33.3 \%)$ & $22(25.3 \%)$ & \\
\hline Yes & $52(66.7 \%)$ & $65(74.7 \%)$ & \\
\hline Adjuvant radiotherapy & & & 0.951 \\
\hline No & $48(61.5 \%)$ & $55(63.2 \%)$ & \\
\hline Yes & $30(38.5 \%)$ & $32(36.8 \%)$ & \\
\hline
\end{tabular}

Data are reported as mean \pm standard deviation or $\mathrm{n}(\%)$

AST, aspartate aminotransferase; ALT, alanine aminotransferase; ALP, alkaline phosphatase; $\gamma \mathrm{GT}$, gamma glutamyl transferase; CEA, carcinoembryonic antigen; CA 19-9, carbohydrate antigen; PTBD, percutaneous transhepatic biliary drainage; ERCP, endoscopic retrograde cholangiopancreatography; ERBD, endoscopic retrograde biliary drainage; ENBD, endoscopic nasobiliary drainage 
were positive for retrieved lymph nodes underwent adjuvant chemotherapy. The regimen was selected according to the physician's preference and/or the patient's condition. The distribution of the main regimen according to period is summarized in Table 1.

\section{Statistical analysis}

Descriptive analyses of the clinical data were conducted using Student's t-test and Pearson's chi-square test. OS was analyzed using the Kaplan-Meier method, and statistical differences were calculated using the log-rank test. OS was calculated from the day of surgery to death or the last follow-up. Statistical significance was set at $p<$ 0.05. Cox proportional hazards regression models were used to determine the association between patient characteristics and OS. All results, except OS analysis, are presented as mean and standard deviation with percentages. The analysis of OS is presented with the median survival (month). To reduce selection bias and the effect of potential confounders, predictive factors were calculated using logistic regression based on age, sex, etiology, surgical procedure, and American Joint Committee on Cancer stage. All statistical analyses were performed using SPSS ${ }^{\circledR}$ for Windows version 22.0 (IBM Corp., Armonk, NY, USA).

\section{RESULTS}

\section{Clinical characteristics according to the period}

In both periods, the patients were predominantly male. The mean patient age was 62.2 and 65.6 years in period I and period II, respectively ( $p=0.021)$. There were no statistically significant differences in terms of liver profile laboratory findings, except serum bilirubin level at diagnosis $(7.6 \pm 6.8$ vs. $5.0 \pm 5.6 \mathrm{mg} / \mathrm{dl}, p=0.008)$. The mean serum CA19-9 level 1 day before surgery was significantly higher in period I than in period II (1306.3 vs. $362.1 \mathrm{U} / \mathrm{ml}$, $p=0.039$ ).

Preoperative percutaneous transhepatic biliary drainage and endoscopic biliary drainage were performed in 63 patients $(80.8 \%)$ and 65 patients $(74.7 \%)$ in periods I and II, respectively. There were no significant differences in the type of hilar cholangiocarcinoma and the proportion of preoperative portal vein embolization between the two periods. Adjuvant chemotherapy (66.7\% vs. $74.7 \%, p=0.335)$ and adjuvant radiotherapy $(38.5 \%$ vs. $36.8 \%, p=0.951)$ were performed during period I and period II (Table 2).

\section{Extent of surgery and concomitant resection}

During period I, 43 patients (53.8\%) underwent right hemihepatectomy, 35 patients $(44.9 \%)$ underwent left hemihepatectomy, and 8 patients $(10.3 \%)$ underwent extended left hemihepatectomy. Further, two patients underwent hepatic artery resection and six patients underwent portal vein resection. During period II, 53 patients (59.9\%) underwent right hemihepatectomy, of whom, 4 patients (4.6\%) underwent extended right hemihepatectomy. None of the patients underwent extended left hemihepatectomy. Central bisectionectomy was performed in two patients $(2.3 \%)$, hepatic artery resection was performed in five patients (5.7\%), and portal vein resection was performed in six patients $(6.9 \%)$ (Table 3).

\section{Pathologic characteristics}

The final pathologic report for the entire study period was classified according to American Joint Committee on Cancer, $8^{\text {th }}$ edition. Regarding $\mathrm{T}$ stage, $\mathrm{T} 2 \mathrm{~b}$ was the most common (53.8\% vs. $50.6 \%$ ), followed by T2a (38.5\% vs. $31.0 \%$ ) in period I and period II. During both periods, three patients with no residual tumor in the resected specimen received neoadjuvant chemoradiotherapy. There were

Table 3. Comparison of the type of surgery between the two groups (period I and period II)

\begin{tabular}{|c|c|c|c|}
\hline \multirow[t]{2}{*}{ Extent of resection } & $\begin{array}{c}\text { Period I } \\
(2005-2011)\end{array}$ & $\begin{array}{c}\text { Period II } \\
(2012-2018)\end{array}$ & \multirow[t]{2}{*}{$p$-value } \\
\hline & $(\mathrm{n}=78)$ & $(\mathrm{n}=87)$ & \\
\hline Type of operation & & & 0.015 \\
\hline $\begin{array}{l}\text { Right } \\
\text { hemihepatectomy }\end{array}$ & $42(53.8 \%)$ & $49(56.3 \%)$ & \\
\hline $\begin{array}{l}\text { Extended right } \\
\text { hemihepatectomy }\end{array}$ & $1(1.3 \%)$ & $4(4.6 \%)$ & \\
\hline $\begin{array}{l}\text { Left } \\
\text { hemihepatectomy }\end{array}$ & $27(34.6 \%)$ & $32(36.8 \%)$ & \\
\hline $\begin{array}{l}\text { Extended left } \\
\text { hemihepatectomy }\end{array}$ & $8(10.3 \%)$ & $0(0.0 \%)$ & \\
\hline $\begin{array}{l}\text { Central } \\
\text { bisectionectomy }\end{array}$ & $0(0.0 \%)$ & $2(2.3 \%)$ & \\
\hline Hepatic artery resection & & & 0.531 \\
\hline No & $76(97.4 \%)$ & $82(94.3 \%)$ & \\
\hline Yes & $2(2.6 \%)$ & $5(5.7 \%)$ & \\
\hline Portal vein resection & & & 1.000 \\
\hline No & $72(92.3 \%)$ & $81(93.1 \%)$ & \\
\hline Yes & $6(7.7 \%)$ & $6(6.9 \%)$ & \\
\hline
\end{tabular}


no significant differences in the number of positive lymph nodes and retrieved lymph nodes between the two periods. The proportion of node metastasis was $43.6 \%$ during period I and 34.4\% during period II. Further, 27 (34.6\%) and 26 (29.8\%) patients had stage III cancer during period I and period II, respectively. R0 resection was performed in 60 patients $(79.5 \%)$ in period I and 60 patients $(69 \%)$

Table 4. Comparison of the pathologic characteristics between the two groups (period I and period II)

\begin{tabular}{|c|c|c|c|}
\hline \multirow[t]{2}{*}{ Variables } & $\begin{array}{c}\text { Period I } \\
(2005-2011)\end{array}$ & $\begin{array}{c}\text { Period II } \\
(2012-2018) \\
\end{array}$ & \multirow[t]{2}{*}{$p$-value } \\
\hline & $(\mathrm{n}=78)$ & $(n=87)$ & \\
\hline $\mathrm{T}$ stage & & & 0.333 \\
\hline No residual tumor & $0(0.0 \%)$ & $3(3.4 \%)$ & \\
\hline 1 & $3(3.8 \%)$ & $6(6.9 \%)$ & \\
\hline $2 \mathrm{a}$ & $30(38.5 \%)$ & $27(31.0 \%)$ & \\
\hline $2 b$ & $42(53.8 \%)$ & $44(50.6 \%)$ & \\
\hline 3 & $1(1.3 \%)$ & $4(4.6 \%)$ & \\
\hline 4 & $2(2.6 \%)$ & $3(3.4 \%)$ & \\
\hline $\begin{array}{l}\text { Number of positive } \\
\text { lymph nodes }\end{array}$ & $1.0 \pm 1.7$ & $0.8 \pm 1.5$ & 0.437 \\
\hline $\begin{array}{l}\text { Number of retrieved } \\
\text { lymph nodes }\end{array}$ & $11.4 \pm 8.1$ & $9.4 \pm 6.2$ & 0.075 \\
\hline $\mathrm{N}$ stage & & & 0.471 \\
\hline 0 & $44(56.4 \%)$ & $57(65.5 \%)$ & \\
\hline 1 & $27(34.6 \%)$ & $23(26.4 \%)$ & \\
\hline 2 & $7(9.0 \%)$ & $7(8.0 \%)$ & \\
\hline AJCC stage & & & 0.104 \\
\hline No residual tumor & $0(0.0 \%)$ & $3(3.4 \%)$ & \\
\hline I & $2(2.6 \%)$ & $4(4.6 \%)$ & \\
\hline II & $42(53.8 \%)$ & $47(54.0 \%)$ & \\
\hline IIIa & $0(0.0 \%)$ & $5(5.7 \%)$ & \\
\hline IIIb & $0(0.0 \%)$ & $1(1.1 \%)$ & \\
\hline IIIc & $27(34.6 \%)$ & $20(23.0 \%)$ & \\
\hline IVa & $7(9.0 \%)$ & $7(8.0 \%)$ & \\
\hline Cell differentiation & & & 0.291 \\
\hline No residual tumor & $0(0.0 \%)$ & $3(3.4 \%)$ & \\
\hline Well differentiated & $11(14.1 \%)$ & $9(10.3 \%)$ & \\
\hline $\begin{array}{l}\text { Moderately } \\
\text { differentiated }\end{array}$ & $56(71.8 \%)$ & $66(75.9 \%)$ & \\
\hline Poorly differentiated & $11(14.1 \%)$ & $9(10.3 \%)$ & \\
\hline Microvascular invasion & & & 0.414 \\
\hline No & $30(38.5 \%)$ & $40(46.0 \%)$ & \\
\hline Yes & $48(61.5 \%)$ & $47(54.0 \%)$ & \\
\hline Perineural invasion & & & 1.000 \\
\hline No & $11(14.1 \%)$ & $13(14.9 \%)$ & \\
\hline Yes & $67(85.9 \%)$ & $74(85.1 \%)$ & \\
\hline Resection status & & & 0.174 \\
\hline $\mathrm{R}_{0}$ & $62(79.5 \%)$ & $60(69.0 \%)$ & \\
\hline $\mathrm{R}_{1}$ & $16(20.5 \%)$ & $27(31.0 \%)$ & \\
\hline
\end{tabular}

Data are reported as mean \pm standard deviation or $\mathrm{n}(\%)$ AJCC, american joint committee on cancer in period II. There were no statistically significant differences between the two periods in terms of $\mathrm{T}$ stage, $\mathrm{N}$ stage, cell differentiation, and histopathologic characteristics (Table 4).

\section{Perioperative outcomes}

There was no significant difference in hospital stay between the two periods. The estimated blood loss was significantly lower during period II than during period I (1528.8 vs. $1034.1 \mathrm{ml}, p=0.020$ ). The proportion of patients who were transfused intraoperatively was also lower during period II than during period I (61.5\% vs. $29.9 \%, p<0.001)$. The postoperative complications were lower during period II than during period I $(p=0.022)$. In both periods, ClavienDindo grade IIIa complication was the most common (33.3\% vs. $16.1 \%$ ). Post-hepatectomy liver failure was not significantly different between the two periods $(p=0.594)$. Regarding postoperative 30-day mortality, six (7.7\%) patients in period I and four (4.6\%) patients in period II died

Table 5. Comparison of the perioperative outcomes between the two groups (period I and period II)

\begin{tabular}{|c|c|c|c|}
\hline \multirow[t]{2}{*}{ Variables } & $\begin{array}{c}\text { Period I } \\
(2005-2011)\end{array}$ & $\begin{array}{c}\text { Period II } \\
(2012-2018)\end{array}$ & \multirow[t]{2}{*}{$p$-value } \\
\hline & $(\mathrm{n}=78)$ & $(\mathrm{n}=87)$ & \\
\hline Hospital stay (days) & $29.6 \pm 19.8$ & $27.8 \pm 46.5$ & 0.748 \\
\hline $\begin{array}{l}\text { Estimated blood loss } \\
(\mathrm{ml})\end{array}$ & $1528.8 \pm 1485.0$ & $1034.1 \pm 1189.2$ & 0.020 \\
\hline Transfusion & & & $<0.001$ \\
\hline No & $30(38.5 \%)$ & $61(70.1 \%)$ & \\
\hline Yes & $48(61.5 \%)$ & $26(29.9 \%)$ & \\
\hline $\begin{array}{l}\text { Post hepatectomy } \\
\text { liver failure }\end{array}$ & & & 0.594 \\
\hline None & $27(34.6 \%)$ & $36(41.4 \%)$ & \\
\hline Grade A & $33(42.3 \%)$ & $35(40.2 \%)$ & \\
\hline Grade B & $12(15.4 \%)$ & $13(14.9 \%)$ & \\
\hline Grade C & $6(7.7 \%)$ & $3(3.4 \%)$ & \\
\hline \multicolumn{2}{|c|}{$\begin{array}{l}\text { Postoperative complication } \\
\text { (Clavien-Dindo classification) }\end{array}$} & & 0.022 \\
\hline None & $23(29.5 \%)$ & $44(50.6 \%)$ & \\
\hline Grade I & $9(11.5 \%)$ & $11(12.6 \%)$ & \\
\hline Grade II & $6(7.7 \%)$ & $9(10.3 \%)$ & \\
\hline Grade IIIa & $26(33.3 \%)$ & $14(16.1 \%)$ & \\
\hline Grade IIIb & $2(2.6 \%)$ & $2(2.3 \%)$ & \\
\hline Grade IVa & $4(5.1 \%)$ & $0(0.0 \%)$ & \\
\hline Grade IVb & $1(1.3 \%)$ & $3(3.4 \%)$ & \\
\hline Grade V & $7(9.0 \%)$ & $4(4.6 \%)$ & \\
\hline 30-day mortality & & & 0.614 \\
\hline No & $72(92.3 \%)$ & $83(95.4 \%)$ & \\
\hline Yes & $6(7.7 \%)$ & $4(4.6 \%)$ & \\
\hline
\end{tabular}


(Table 5).

\section{Survival analysis according to the period, and cox regression analysis of factors affecting OS}

The median survival duration was 25 months (95\% confidence interval $[\mathrm{CI}]=19.807-30.193)$ and 42 months $(95 \%$ $\mathrm{CI}=27.540-56.460)$ in period I and period II, respectively. The 5-year survival rate was $21.0 \%$ and $35.1 \%$ in period I and period II, respectively. The difference in survival duration was statistically significant ( $p=0.0071$ ) (Fig. 1).

The univariate and multivariate analyses of factors related to survival are summarized in Table 6. During period I (hazard ratio $[\mathrm{HR}]=1.591 ; 95 \% \mathrm{CI}=1.049-2.414 ; p=$ $0.029)$, preoperative serum bilirubin level at diagnosis $(\mathrm{HR}=$ 1.585; 95\% CI=1.058-2.374; $p=0.026$ ), and tumor stage (III and IV) ( $\mathrm{HR}=1.671 ; 95 \% \mathrm{CI}=1.133-2.464 ; p=0.010)$ were significantly associated with poor prognosis. Preoperative serum CA 19-9 level, lymph node metastasis, and adjuvant chemotherapy were significant in univariate analysis but not in multivariate analysis.

\section{DISCUSSION}

Despite the efforts to improve the oncological outcome of hilar cholangiocarcinoma, the actual 5-year survival rate has remained low at $14 \%-45 \%{ }^{14}$ In our series, the 5 -year survival rate was $35.1 \%$ in the period II group and $21.0 \%$ in the period I group. Several studies have reported chronological improvement and evolution in the surgical

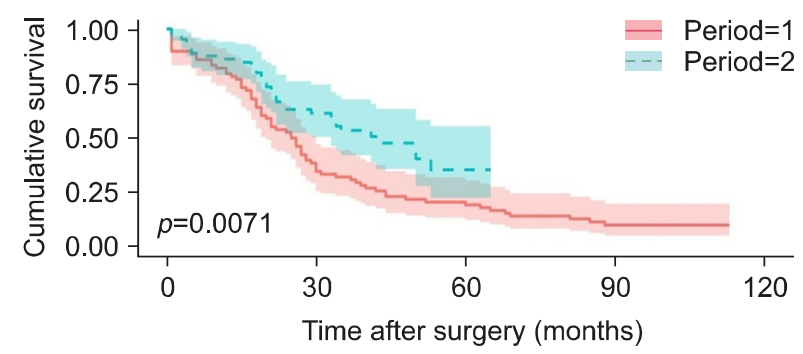

Period $=1-$\begin{tabular}{ccccc} 
Number at risk \\
78 & 30 & 16 & 6 & 0 \\
87 & 34 & 3 & 0 & 0 \\
\hline 0 & 30 & 60 & 90 & 120 \\
& & & & \\
& Time after surgery (months)
\end{tabular}

Fig. 1. Overall survival analysis according to period.

Table 6. Univariate and multivariate regression analyses of prognostic factors for overall survival

\begin{tabular}{|c|c|c|c|c|c|}
\hline \multirow{2}{*}{ Variables } & \multicolumn{2}{|c|}{ Univariate } & \multicolumn{3}{|c|}{ Multivariate analysis } \\
\hline & $p$-value & HR & $p$-value & HR & $95 \%$ CI \\
\hline Period I & 0.009 & 1.741 & 0.029 & 1.591 & $1.049-2.414$ \\
\hline Sex (male) & 0.098 & 1.744 & & & \\
\hline Age $(>60$ years $)$ & 0.783 & 1.003 & & & \\
\hline $\begin{array}{l}\text { Preoperative serum albumin } \\
(<3.5 \mathrm{~g} / \mathrm{dl})\end{array}$ & 0.195 & 1.529 & & & \\
\hline $\begin{array}{l}\text { Preoperative serum bilirubin at } \\
\text { diagnosis }(>3 \mathrm{mg} / \mathrm{dl})\end{array}$ & 0.021 & 1.605 & 0.026 & 1.585 & $1.058-2.374$ \\
\hline $\begin{array}{l}\text { Preoperative serum CA 19-9 at } \\
\text { diagnosis }(>400 \mathrm{U} / \mathrm{ml})\end{array}$ & 0.009 & 2.590 & 0.182 & 1.322 & $0.877-1.991$ \\
\hline Preoperative cholangitis & 0.263 & 0.800 & & & \\
\hline Right hemihepatectomy & 0.815 & 0.955 & & & \\
\hline Estimated blood loss $(>1000 \mathrm{ml})$ & 0.284 & 1.234 & & & \\
\hline Transfusion & 0.224 & 0.786 & & & \\
\hline Postoperative liver failure (PHLF B, C) & 0.513 & 0.773 & & & \\
\hline $\mathrm{R}$ status $(\mathrm{R} 1)$ & 0.688 & 0.911 & & & \\
\hline MVI & 0.142 & 0.746 & & & \\
\hline PNI & 0.455 & 0.816 & & & \\
\hline Lymph node metastasis & 0.033 & 1.522 & 0.591 & 1.788 & $0.330-1.882$ \\
\hline Adjuvant chemotherapy & 0.083 & 1.447 & 0.092 & 1.059 & $0.452-1.062$ \\
\hline Adjuvant radiotherapy & 0.294 & 0.810 & & & \\
\hline Tumor stage (III, IV) & 0.006 & 1.724 & 0.010 & 1.671 & $1.133-2.464$ \\
\hline
\end{tabular}

CA 19-9, carbohydrate antigen 19-9; MVI, microvascular invasion; PNI, perineural invasion; HR, hazard ratio; CI, confidence interval 
and oncological outcomes of hilar cholangiocarcinoma. ${ }^{15,16}$ Significant improvements were observed as the period progressed; however, the gap between the two periods is $>25$ years. Since the investigated period is long, the analysis of contributing prognostic factors can be strongly influenced by various biases. Therefore, it is necessary to analyze the change over a relatively short period and investigate the changes caused by the differences. In this series, we set the analyzing and comparing period as 6 years.

We found that period I was a significant prognostic factor for OS. The significant difference in OS between periods I and II may have resulted from the operative factors and perioperative support. These chronological and oncological improvements in patients with surgically resected hilar cholangiocarcinoma have been shown in previous studies. ${ }^{9,17}$ Compared to patients in the period I group, those in the period II group had lower serum CA 19-9 levels immediately prior to the surgery. Although there was no statistically significant difference between the two groups, the higher proportion of preoperative cholangitis and neoadjuvant chemotherapy in the period II group may have affected the preoperative CA 19-9 levels. Three patients who received neoadjuvant chemotherapy reported no residual tumor in the final pathologic report. Regarding intraoperative factors, the number of extended right hemihepatectomies and central bisectionectomies in the period II patients was significantly higher than that in the period I patients, whereas extended left hemihepatectomy was performed more frequently in the period I patients. Nevertheless, there were no significant differences in terms of hospital stay, postoperative 30-day mortality, and postoperative liver failure rate; however, the period II group showed better outcomes in terms of estimated blood loss and the blood transfusion and postoperative complication rates. Previous studies have reported that operative morbidity and oncological outcomes of biliary-pancreatic malignancy are associated with intraoperative blood loss and blood transfusion. ${ }^{18-20}$ The association between blood transfusion and long-term survival after resection for perihilar cholangiocarcinoma has been examined previously. ${ }^{9,21}$ The specific mechanism leading to the adverse effect of blood transfusion is unclear, but experimental and clinical studies have demonstrated that blood transfusion suppresses host immunity by reducing natural killer cell activity and cytotoxic $\mathrm{T}$ cell function.
Regarding radical resection status, the $\mathrm{R} 0$ resection rate of the period II group was lower than that of the period I group. Several previous studies that conducted a chronological analysis of the surgical outcomes following the treatment of perihilar cholangiocarcinoma reported that the R0 resection rate was $73 \%-79 \% .^{9,15-17}$ Since the previous studies included all R2 status, the ratio will be lower in the comparison between R0 and R1 only. However, the rate of $\mathrm{R} 0$ resection increased as the period progressed. In the current study, the spectrum of patients was clinically expanded with the results from increased proportion of portal vein embolization and adjuvant therapy. In addition, ratio of Bismuth type III-IV (83.3\% vs. $87.3 \%)$ in the preoperative diagnosis was increased.

Preoperative serum bilirubin levels, which are known to reflect liver status and surgical extension, ${ }^{8}$ were also an important factor for OS in this study; however, there was no significant difference in bilirubin levels in the between-period comparison. The presence of lymph node metastasis is an important independent predictor of longterm survival, ${ }^{5,22}$ although it showed no statistical significance. However, among the TNM stages, which are extended concept including tumor extent and lymph node metastasis, advanced stage (III and IV) was an important prognostic factor.

In recent years, surgical treatment for hilar cholangiocarcinoma has been evolving steadily, with an expanded indication, decreased mortality, and increased survival. Previous studies have reported lymph node metastasis, histopathologic status, resection margin status, and adjuvant chemotherapy as important prognostic factors for resected hilar cholangiocarcinoma. ${ }^{22-25}$ Recently, studies on neoadjuvant therapy have been conducted as a bridge modality to improve the rate of radical resection of locally advanced hilar cholangiocarcinoma. ${ }^{26-28}$ In view of these trends, especially those from 2000, the impact of surgical skills and methods remains important; however, the perioperative support and management are also thought to contribute to the oncological outcomes in patients with hilar cholangiocarcinoma.

In conclusion, the surgical and oncological outcomes have improved in patients with hilar cholangiocarcinoma, and the survival rate is expected to improve in the coming years, including that of patients with radical and concomitant vascular resections. The liver status, predicted by 
preoperative serum bilirubin levels, and advanced tumor stage, including tumor extension, are associated with poor prognosis in patients with hilar cholangiocarcinoma. However, there is limited evidence to accurately predict the prognosis with the currently known factors, and it is important to select a surgical candidate in consideration of the preoperative liver status and tumor extension.

\section{CONFLICT OF INTEREST}

The authors have no conflicts of interest to disclose.

\section{ORCID}

Sung Ho Lee: https://orcid.org/0000-0002-7960-0441

Gi Hong Choi: https://orcid.org/0000-0002-1593-3773

Dai Hoon Han: https://orcid.org/0000-0003-2787-7876

Kyung Sik Kim: https://orcid.org/0000-0001-9498-284X

Jin Sub Choi: https://orcid.org/0000-0002-6467-6494

Seoung Yoon Rho: https://orcid.org/0000-0002-1265-826X

\section{AUTHOR CONTRIBUTIONS}

Conceptualization: GHC, SYR. Data collection: SHL, GHC, DHH, KSK, JSC. Data analysis: SHL, SYR. Methodology: SHL, GHC. Writing: SHL. Review and finalization: SYR.

\section{REFERENCES}

1. Neuhaus P, Jonas S, Bechstein WO, Lohmann R, Radke C, Kling $\mathrm{N}$, et al. Extended resections for hilar cholangiocarcinoma. Ann Surg 1999;230:808-818; discussion 819.

2. Iwatsuki S, Todo S, Marsh JW, Madariaga JR, Lee RG, Dvorchik I, et al. Treatment of hilar cholangiocarcinoma (Klatskin tumors) with hepatic resection or transplantation. J Am Coll Surg 1998; 187:358-364.

3. Nimura Y, Kamiya J, Nagino M, Kanai M, Uesaka K, Kondo $\mathrm{S}$, et al. Aggressive surgical treatment of hilar cholangiocarcinoma. J Hepatobiliary Pancreat Surg 1998;5:52-61.

4. Mizuno T, Ebata T, Nagino M. Advanced hilar cholangiocarcinoma: an aggressive surgical approach for the treatment of advanced hilar cholangiocarcinoma: perioperative management, extended procedures, and multidisciplinary approaches. Surg Oncol 2020;33:201-206.

5. Kang MJ, Jang JY, Chang J, Shin YC, Lee D, Kim HB, et al. Actual long-term survival outcome of 403 consecutive patients with hilar cholangiocarcinoma. World J Surg 2016;40:2451-2459.

6. Tran TB, Ethun CG, Pawlik TM, Schmidt C, Beal EW, Fields $\mathrm{RC}$, et al. Actual 5-year survivors after surgical resection of hilar cholangiocarcinoma. Ann Surg Oncol 2019;26:611-618.

7. Klempnauer J, Ridder GJ, von Wasielewski R, Werner M, Weimann A, Pichlmayr R. Resectional surgery of hilar cholangiocarcinoma: a multivariate analysis of prognostic factors. J Clin Oncol 1997; 15:947-954.

8. Su CH, Tsay SH, Wu CC, Shyr YM, King KL, Lee CH, et al. Factors influencing postoperative morbidity, mortality, and survival after resection for hilar cholangiocarcinoma. Ann Surg 1996;223:384-394.

9. Liu CL, Fan ST, Lo CM, Tso WK, Lam CM, Wong J. Improved operative and survival outcomes of surgical treatment for hilar cholangiocarcinoma. Br J Surg 2006;93:1488-1494.

10. Han SS, Jang JY, Lee KU, Kim SW. Actual long-term outcome of Klatskin's tumor after surgical resection. Hepatogastroenterology 2008;55:1986-1992.

11. Bismuth H, Nakache R, Diamond T. Management strategies in resection for hilar cholangiocarcinoma. Ann Surg 1992;215:31-38.

12. Clavien PA, Barkun J, de Oliveira ML, Vauthey JN, Dindo D, Schulick RD, et al. The Clavien-Dindo classification of surgical complications: five-year experience. Ann Surg 2009;250:187-196.

13. Rahbari NN, Garden OJ, Padbury R, Brooke-Smith M, Crawford M, Adam R, et al. Posthepatectomy liver failure: a definition and grading by the International Study Group of Liver Surgery (ISGLS). Surgery 2011;149:713-724.

14. Nuzzo G, Giuliante F, Ardito F, Giovannini I, Aldrighetti L, Belli $\mathrm{G}$, et al. Improvement in perioperative and long-term outcome after surgical treatment of hilar cholangiocarcinoma: results of an Italian multicenter analysis of 440 patients. Arch Surg 2012;147:26-34.

15. Nagino M, Ebata T, Yokoyama Y, Igami T, Sugawara G, Takahashi Y, et al. Evolution of surgical treatment for perihilar cholangiocarcinoma: a single-center 34-year review of 574 consecutive resections. Ann Surg 2013;258:129-140.

16. Lee SG, Song GW, Hwang S, Ha TY, Moon DB, Jung DH, et al. Surgical treatment of hilar cholangiocarcinoma in the new era: the Asan experience. J Hepatobiliary Pancreat Sci 2010;17: 476-489.

17. Furusawa N, Kobayashi A, Yokoyama T, Shimizu A, Motoyama H, Miyagawa S. Surgical treatment of 144 cases of hilar cholangiocarcinoma without liver-related mortality. World J Surg 2014;38:1164-1176.

18. Nagino M, Kamiya J, Arai T, Nishio H, Ebata T, Nimura Y. One hundred consecutive hepatobiliary resections for biliary hilar malignancy: preoperative blood donation, blood loss, transfusion, and outcome. Surgery 2005;137:148-155.

19. Hwang HK, Jung MJ, Lee SH, Kang CM, Lee WJ. Adverse oncologic effects of intraoperative transfusion during pancreatectomy for left-sided pancreatic cancer: the need for strict transfusion policy. J Hepatobiliary Pancreat Sci 2016;23:497-507.

20. Kimura N, Toyoki Y, Ishido K, Kudo D, Yakoshi Y, Tsutsumi $\mathrm{S}$, et al. Perioperative blood transfusion as a poor prognostic factor after aggressive surgical resection for hilar cholangiocarcinoma. J Gastrointest Surg 2015;19:866-879.

21. Young AL, Igami T, Senda Y, Adair R, Farid S, Toogood GJ, et al. Evolution of the surgical management of perihilar cholangiocarcinoma in a Western centre demonstrates improved survival with endoscopic biliary drainage and reduced use of blood transfusion. HPB (Oxford) 2011;13:483-493.

22. Jang JY, Kim SW, Park DJ, Ahn YJ, Yoon YS, Choi MG, et al. Actual long-term outcome of extrahepatic bile duct cancer after surgical resection. Ann Surg 2005;241:77-84.

23. Capussotti L, Muratore A, Polastri R, Ferrero A, Massucco P. Liver resection for hilar cholangiocarcinoma: in-hospital mortality and longterm survival. J Am Coll Surg 2002;195:641-647. 
24. Pichlmayr R, Weimann A, Klempnauer J, Oldhafer KJ, Maschek $\mathrm{H}$, Tusch G, et al. Surgical treatment in proximal bile duct cancer. A single-center experience. Ann Surg 1996;224:628-638.

25. Todoroki T, Kawamoto T, Koike N, Takahashi H, Yoshida S, Kashiwagi $\mathrm{H}$, et al. Radical resection of hilar bile duct carcinoma and predictors of survival. Br J Surg 2000;87:306-313.

26. Jung JH, Lee HJ, Lee HS, Jo JH, Cho IR, Chung MJ, et al. Benefit of neoadjuvant concurrent chemoradiotherapy for locally advanced perihilar cholangiocarcinoma. World J Gastroenterol
2017;23:3301-3308.

27. Sumiyoshi T, Shima Y, Okabayashi T, Negoro Y, Shimada Y, Iwata J, et al. Chemoradiotherapy for initially unresectable locally advanced cholangiocarcinoma. World J Surg 2018;42:29102918.

28. Katayose Y, Nakagawa K, Yoshida H, Morikawa T, Hayashi H, Okada $\mathrm{T}$, et al. Neoadjuvant chemoradiation therapy for cholangiocarcinoma to improve R0 resection rate: the first report of phase II study. J Clin Oncol 2015;33(3 Suppl):402. 